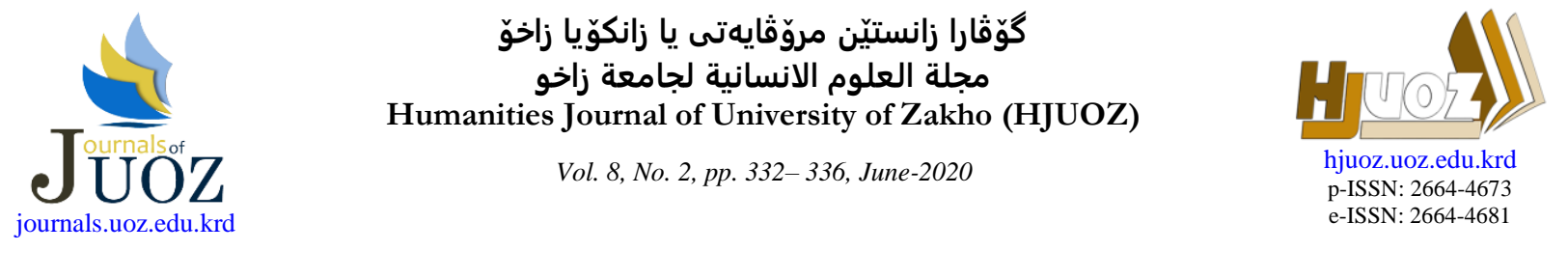

\title{
Learning Vocabularies through Semantic Mapping Strategy
}

\author{
Fakhir Omar Mohammed*, Sanan Shero Malo \\ Dept. of English languages, Faculty of Humanities, University of Zakho, Kurdistan Region-Iraq.
}

Received: 05. 2020 / Accepted: 06. 2020 / Published: 06. 2020 https://doi.org/10.26436/hjuoz.2019.8.2.607

\begin{abstract}
:
This paper aimed at studying the effect of semantic map (also known as mind map) on the students' awareness and mastery of new vocabulary on different topics. The study is based on data collected from pre and post-tests administered to a sample of third year students form Dept. of English, Faculty of Humanities, University of Zakho. the study has adopted Gunning strategy (1992) in applying the effect of semantic mapping on students' learning vocabularies. Moreover, to conduct the present study, two tools fro data collection were used, namely a test and classroom observation. The data collected were analysed using Software SPSS. Finally, the paper concluded that such strategy had no effect on the students' learning vocabulary.
\end{abstract}

Keywords: learning vocabularies, students' awareness, semantic map.

\section{Introduction}

The word mastery strategy that is used in the current study is the semantic mapping (hence, SM) presented and developed by some educationalists, including Bromley (1992) and Rubin (1993). The strategy focuses on how words and vocabularies are semantically related to each other and finally categorized. In other words, the strategy concentrates on organizing brainstormed information graphically on semantic maps. Here, the SM helps the students with mastering vocabularies to get knowledge of the meanings of vocabularies. That is to say, students can benefit from vocabulary development and assessment via the SM. Likewise, Zemach and Islam (2006) mentioned that a semantic map can help students think of many ideas for one's writing and see connections between ideas. As a matter of fact, the students find it difficult to deal with vocabulary without using a strategy to enable them provide and remember vocabulary easily.

\section{Aims}

The study aimed at:

1. Assessing vocabulary mastery via word awareness skills of EFL university students.

2. Measuring the effect of the SM strategy on the word awareness level.

\section{Research Questions}

The following research question has been set for conducting the study:

Do semantic mappings have a statistically significant effect on students' learning vocabularies?

\section{The Hypotheses}

Based on the research question, the following hypotheses were set to be tested against the results which will be arrived at in the present study.

1. The Null Hypothesis

There is no statistically significant difference between the mean scores of the pre and posttest.

2. The alternative hypothesis
There is a statically significant effect on the students' learning vocabularies.

\section{Limitation of the Study}

The current paper is limited to the application of the SM strategy to help the third-year students of the English Department, University of Zakho, develop their skills in the awareness of how to develop their vocabularies, especially those that are related to lexical semantics topics.

\section{Significance of the Study}

In spite of conducting a lot of research on the semantic awareness of words, skills, activities, strategies and assessment, research on mastering and comprehending vocabularies is open to investigation To the best knowledge of the researchers, the use of the SM strategy to master the vocabularies (i.e. lexical semantics topics) with Kurdish university students has not been tackled before. Therefore, it is very important to explain, assess and measure the SM strategy, showing the learners' performance on the awareness of lexical semantics topics. The present study will hopefully help EFL students to learn new vocabulary more easily based on the strategy of semantic map since the students encounter difficulty to provide different vocabulary and remember them easily when dealing with topics, for example, in reading or writin. Furthermore, the study can help studens studying other major including secience, business, medicine,etc.

\section{The Concept of Vocabulary}

The term vocabulary has been defined in different ways and perspectives. Hornby (1995:1331) has stated that vocabulary is the total number of words which (with rules of combining them) make up a language. In addition, Dupuis et al (1989: 67) have stated that vocabulary refers to "a set of words or phrases which label the parts of material to be learned and which are necessary for students to use in talking and writing about the material."

Vocabulary mastery is a great skill of gettin knowledge about a set of words known by a person as a part of specific language. Vocabulary mastery is crucial to language acquisition.

${ }^{*}$ Corresponding Author. 
Moreover, Levine (1965:1) has stated that "research has established a close correlation between vocabulary and intelligence". This means that the students' intelligence is determined by using different methods and strategies. The students can improve their vocabulary mastery when they follow strategies like the SM strategy. It helps them to find new words and know their meanings in different context. Hence, by brainstorming and drawing maps, their vocabulary will develop greatly.

\section{Lexical Semantics Topics for EFL Students}

The discipline of semantics covers a variety of topics given to EFL students in any course book. Hence, the semantic topics given to the third year students in the English Department, School of Languages, University of Zakho, are included in the following table:

Table 1: Semantics Topics for EFL Students

\begin{tabular}{|c|l|l|}
\hline No. & \multicolumn{1}{|c|}{$\begin{array}{c}\text { Lexical Semantics } \\
\text { Topics }\end{array}$} & \multicolumn{1}{c|}{ Purpose } \\
\hline 1 & Sense vs. reference & $\begin{array}{l}\text { To show the relationship between linguistic elements (words, } \\
\text { phrases and sentences) and non-linguistic elements (objects and } \\
\text { entities). }\end{array}$ \\
\hline 2 & Sense relations & $\begin{array}{l}\text { To divide the sense (lexical) relations into synonymy, } \\
\text { antonyms, hyponymy, homonymy, taxonomy, etc. }\end{array}$ \\
\hline
\end{tabular}

As shown in the above table, only the lexical semantics topics (i.e. sense relations including synonymy, antonyms, hyponymy, homonymy, taxonomy, etc.) were used as categorized content for showing the applicability and functionality of the SM strategy, allocating much more time to the students' role, group discussions and mini presentations by the students. In brief, such a strategy is a very significant tool in stimulating the EFL learners work together as one unity, getting remarkable benefits from their classroom interaction. The topics understudy covered the following sense relations. First, synonyms are sense relations that refer to the sameness of meaning between lexical items. For instance, pairs such as dad/father, nice/pretty, wonderful/magnificent, fall/autumn, big/large, freedom/liberty, among many others, are synonymous in their meanings. However, these synonyms are not absolute (Yule, 2006: 104). This means they cannot be substituted for each other in the same sentences or contexts. For example, the word reply cannot be used instead of answer in the question Can you answer my question?

The other sense realtion covered in this study is antonyms which are lexical items that are opposite in their meanings (Yule, 2006: 104). Examples of antonymys include wide/narrow, happy/sad, doctor/patient, male/female, give/take, buy/sell, left/right, top/button, etc. Fromkin and Rodman (1983: 177) claim that antonymous lexical items should have "semantic properties in common". For instance, big and red are not considered antonyms because big possesses a semantic property involving size, whereas red involves color. Moreover, hyponymy is a sense relation where a specific item is included in a more general item. For example, the lexical items rose, daffodil and tulip are considered members (i.e. hyponyms) of one linguistic class, which is flower. According to Yule (2006: 106), the relation of hyponymy captures the concept of "is a kind of". For instance, we can say that a rose is a kind of flower.

Finally, homonymy can be defined as a sense relation that holds between lexical items that have the same pronunciation and spelling but different unrelated meanings. For instance, pupil has two dictionary entries. One entry means $a$ student, while the other one refers to a part of eye. According to Yule (2006: 106), sometimes lexical words are partially homonymous, that is, they have the same pronunciation but different spellings. Examples include meat/meet, sea/see, flour/flower, right/write/rite, to/two/too, and others.

\section{Semantic Mapping Strategy}

Bromley (1992:218) has mentioned that a semantic map or web is a graphic representation of categories of information and their relationship to each other. The same idea has been supported by Gunning (1992:162), stating that semantic mapping "can be used for concepts, vocabulary, topics and background". While Rubin (1993) has stated that

Semantic mapping is a technique for organizing information: it helps to give structure or order. It helps people to see the relationship among concepts, and it shows the various ways that information can be organized and categorized in more general or more specific categories. (79)

The following figure represents an example of semantic map:

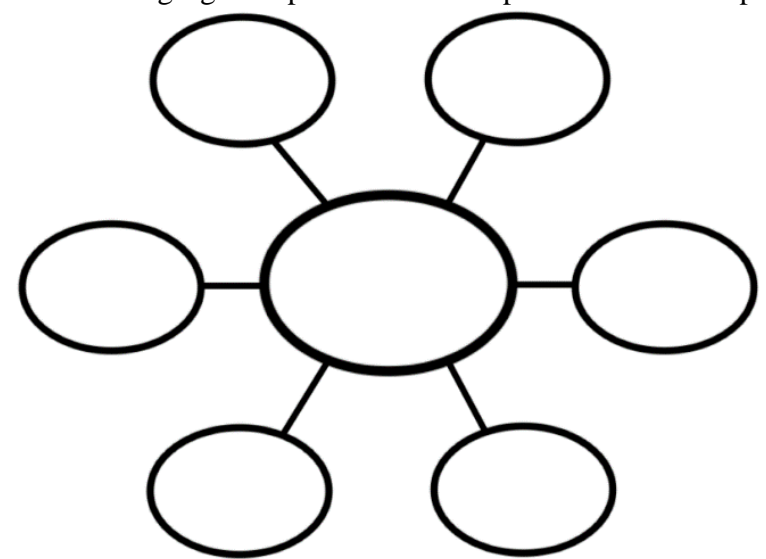

Figure 1: A Sample of Semantic Map (Adapted after Jordan, 1999: 32)

Like any other strategy used in the teaching process, the SM strategy has several advantages as listed by Rubin (1993:175176):

1. The SM strategy enables the students to remember the words and their connection easily due to presenting a visual representation of the material.

2. The SM strategy is an interactive learning process into which all the students can be involved. Feeling secure as they use their previous knowledge will make them ready to involve in the teaching and learning process.

3. This strategy is used to motivate and involve students in the thinking, reading and writing aspects. They think of the words and they will come up with other related words, then they will try to write the spelling of the words. Students remember not only the meaning but also the spelling.

4. This strategy helps the students become independent learners by brainstorming different topics when doing tasks indiviaully, in groups or in pairs.

5. The SM strategy enhances vocabulary development by helping students link new information with previous experience.

Phongploenpis and Supangyut (2018:50) have stated that mind map helps learners to focus on key words and concepts which often be hidden in leaner notes, to store related facts together, to be aware of hierarchies, it helps in decision making because 
it allows learners to look at all the complex and inter-related information learners need to consider, to recognize and plan their objectives for a meeting, presentation or project. It also encourages creative thinking, to help in problem solving because it encourages learns to think of all possible aspects of a problem and various potential solution.

\section{Procedure of the Semantic Mapping Strategy}

To teach SM strategy and to attain vocabulary development, the procedures presented by Gunning (1992:164) and Buzan (2000, p.70) (as cited in Phongploenpis \& Supangyut, 2018) for this strategy were followed:

1. Placing an image or a topic in the center.

2. Using images, symbols, codes, and dimensions.

3. Writing keys for the topic.

4. Putting each word/image as a category on its own line.

5. Connecting the words using lines starting from the central.

6. Making central lines thicker as organic, and flowing, then becoming thinner as they radiate out form the center.

7. Making the lines of the same length as the word image

8. Using a variety of colors throughout mind mapping.

9. Using emphasis to show associations in the SM.

10. Keeping the SM clear using redial hierarchy, numerical, or order outlines to embrace the branches.

The test used in the present study was a part of the procedures followed in giving the lecture and was ralted to the topic covered in the lectue since an essential part of any lecture was devoted to assessment. Moreoevr, the test was arranged to fit the context of the lecture. The students' performance on reading skills was determined by scores obtained on the two exams. Both the two exams were compared by a series of t-tests and multiple comparison correlations. Phongploenpis and Supangyut (2018) conducted a quasi-experimental study using mind map technique in teaching reading comprehension to a group of students. They found that there was a significant effect of mind mapping technique on the students' reading comprehension. Likewise, Zahedi and Abdi (2012) conducted a study using semantic mapping in teaching

\section{Method}

To conduct this study, the researchers have adopted the technique of observation and evaluation. For this purpose, Preand posttests were administered to a sample of 28 juniors (18 males, 10 females) who were enrolled in a class of explaining the lexical semantics topics at the English Department, Faculty of Humanities, University of Zakho. This class lasted for one hour and it was arranged especially for the purpose of the present study. In order to assess the students' awareness of vocabulary development related to lexical semantic topics, the researchers followed the procedure shown below:

1. Lexical semantics topics were explained to the students in a traditional method.

2. The students had their first exam on lexical semantics topics (pre-test).

3. The same topic was further explained by adopting the SM strategy.

4. The students had their second exam on lexical semantics topics (post-test).

5. The results of the two exams were compared to each other to see whether any learning progress has been achieved according to the new strategy or not.

In this class, one of the researchers observed the process of teaching and learning closely. Following the teacher's instructions and explanations, the students understood the material better.

\section{Results}

After explaining sense relations as lexical semantics topics to the students and applying the procedures of the SM strategy, One of the researchers evaluated the students. Two exams (preand posttests) out of 20 scores were administered. Then the data were analyzed by using the t-test and multiple comparisons, which were run by Software SPSS. The results are discussed in the following subsections. Mean and standard deviation of the scores obtained on pretest $($ Mean $=12.39)$, which was administered before applying the SM strategy, and posttest (Mean $=11.50)$ administered after assessing the strategy, are presented in Table 2 below:

Table 2 Mean and standard deviation of scores obtained on Exam 1 and Exam 2.

\begin{tabular}{|c|c|c|c|c|}
\hline Exams & Mean & $\mathrm{N}$ & Std. Deviation & Std. Error Mean \\
\hline Pretest & 12.50 & 28 & 2.457 & .464 \\
\hline Posttest & 11.50 & 28 & 2.236 & .423 \\
\hline
\end{tabular}

There is no such a remarkable difference between the means of score averages calculated in the two exams (See Appendix 1 for the difference between these scores). Hence, it was necessary to calculate the p-value in order to show the statistical significance.

In conducting a paired t-test by SPSS, the results showed that the mean difference was not statistically significant at the 0.05 level. This is clear from Table 3 below: $\mathrm{Sig}=.095, \mathrm{p}>0.05$. In other words, the students enrolled in class of lexical semantics topics did not perform a wider range of abilities in understanding the lexical semantics topics after adopting the SM strategy. Here, it can be concluded that the alternative hypothesis is rejected and the null hypothesis is accepted. That is to say, the SM strategy is not effective in developing the students' awareness of lexical semantic topics.

Table 3 Significance and mean difference of scores obtained on Pre- and Posttests.

\begin{tabular}{|c|c|c|c|c|c|c|c|c|}
\hline & \multicolumn{5}{|c|}{ Paired Differences } & \multirow{3}{*}{ t } & \multirow{3}{*}{ Df } & \multirow{3}{*}{ Sig. (2-tailed) } \\
\hline \multirow{3}{*}{$\begin{array}{l}\text { Pre- and } \\
\text { Posttests }\end{array}$} & \multirow{2}{*}{ Mean } & \multirow{2}{*}{ Std.Deviation } & \multirow{2}{*}{ Std.Error Mean } & \multicolumn{2}{|c|}{$\begin{array}{l}\text { 95\% Confidence Interval of the } \\
\text { Difference }\end{array}$} & & & \\
\hline & & & & Lower & Upper & & & \\
\hline & 1.000 & 3.055 & .577 & $-.185-$ & 2.185 & 1.732 & 27 & .095 \\
\hline
\end{tabular}

\section{Discussion}

In the present study, the participants did two exams out of 20 scores. One exam was done in a traditional method such as the lecture style, where the teacher defined the lexical semantics topics (e.g. hyponymy, homonymy, synonymy, etc.), explained everything related to them, and gave the students examples. The second exam was done on the same topics after adopting the SM strategy with an interval of one week after delivering the lecture. In conducting a paired t-test calculation by SPSS, the results showed that the students did not develop their skills in the awareness of lexical semantics topics. Their abilities in the two exams appeared not to vary much over time. This is obvious from the mean differences in Table (2). In 
addition, the alternative hypothesis is rejected because there was no statistical significance ( $\mathrm{Sig}=.095, \mathrm{p}>0.05$ ) between the score averages obtained from the two exams. This suggests that the SM strategy did not effectively work with the sample under study to understand and develop the awareness of lexical semantics topics. As it is clear from the results arrived at, the null hypothesis was verified and accepted, whereas the alternative hypothesis was rejected. This might be due to the students' level or their educational background. On the other hand, the results arrived at in the present study were not in agrrement with the results obtained by Phongploenpis and Supangyut (2018) and Zahedi and Abdi (2012) .

\section{Conclusions}

The present study arrived at the following concluding remarks: 1. According to the mean differences, the results obtained from the pretest were better than those recorded for the posttest. 2. The SM strategy was not effective in developing the students' awareness and understanding of lexical semantics topics.

\section{Recommendations}

For further research can be done on the lexical semantics topics, developing the awareness of such a concept in university context, and making the SM strategy more effective in the learning process, the researchers recommend the following:

1. Since other language skills such as writing and reading require brainstorming new ideas and vocabularies, teachers can makes use of this strategy to develop students' skills in these two language skills at university level.

2. Consulting other learning strategies in developing the awareness of lexical semantics topics at more advanced levels.

\section{Suggestions for Further Research}

The following topics can be investigated using semantic mapping strategy after making some adaptations with teaching methods and providng the students with a good learning to motivate them.
1. Investigating students' awareness of food vocabulary reading at elementary level.

2. Studying EFL Students' awareness of weather vocualbry in writing at university level.

3. Evaluating EFL students' feedback of using semantic mapping in developing speaking skills at university level.

\section{References}

- Bromley, K. D. (1992). Language Arts: Exploring Connection (2nd Ed.). Boston, MA: Allyn \& Bacon, a Division of Simon and Schuster, Inc.

- Dupuis, Mary M., Lee, Joyce W., Badiali, Bernard J., Askov \& Eunice N. (1989). Teaching Reading and Writing in the Content Area. New York, NY: Scott Foresman Company. - Fromkin, Victoria and Rodman, Robert (1983). An Introduction to Language. 3rd ed. USA: CBS College Publishing.

- Gunning, T. G. (1992). Creating Reading Instruction for all Children. London: Allyn and Bacon.

- Hornby, A.S. (1995). Oxford Advanced Learners Dictionary of Current English. London: Oxford University Press.

- Jordan, R. R. (1999). Academic Writing Course: Study Skills in English. Essex: Longman.

- Levine, H. (1965). Vocabulary for the College-Bound Students. New York, NY: Amsco School Publication.

- Phongploenpis, S. \& Supangyut, M. (2018). The Effect of Mind Map Technique on Students' Reading Comprehension. [Online] International Journal of Management and Applied Science. 4 (12). 49-53.

- Rubin, D. (1993). Teaching Reading and Study Skills in Content Area. Boston, MA: Allyn and Bacon, a Division of Simon and Schuster, Inc.

- Yule, G. (2006). The Study of Language. 3rd ed. Cambridge: Cambridge University Press.

- Zahedi and Abdi (2012) The effect of semantic mapping strategy on EFL learners' vocabulary learning. Procedia Social and Behavioral Sciences 69 ( 2012 ) 2273 - 2280. doi: 10.1016/j.sbspro.2012.12.198

- Zemach, D. E. \& Islam, C. (2006). Writing in Paragraphs. Oxford: Macmillan. 
Appendix 1

The results obtained on both pre and post tests

\begin{tabular}{|c|c|}
\hline Pre-test & Post-test \\
\hline 11 & 11 \\
\hline 17 & 12 \\
\hline 12 & 13 \\
\hline 15 & 14 \\
\hline 11 & 12 \\
\hline 17 & 15 \\
\hline 17 & 17 \\
\hline 12 & 19 \\
\hline 16 & 20 \\
\hline 14 & 12 \\
\hline 15 & 13 \\
\hline 16 & 15 \\
\hline 19 & 12 \\
\hline 17 & 17 \\
\hline 11 & 16 \\
\hline 11 & 15 \\
\hline 16 & 15 \\
\hline 16 & 15 \\
\hline 10 & 12 \\
\hline 16 & 8 \\
\hline 16 & 14 \\
\hline 17 & 14 \\
\hline 16 & 16 \\
\hline 13 & 13 \\
\hline 14 & 11 \\
\hline 19 & 17 \\
\hline 12 & 11 \\
\hline 13 & 11 \\
\hline & \\
\hline
\end{tabular}

تعلم المفردات من خلال استراتيجية الخرائط الدلالية

تهدف هذه الدراسة إلى تقييم تأثير استراتيجية الخريطة الدلالية (أو الخريطة الذهنية) على وعي الطلاب وإتقان المفردات الجديدة حول مواضيع مختلفة. تعتمد نتائج الدراسة

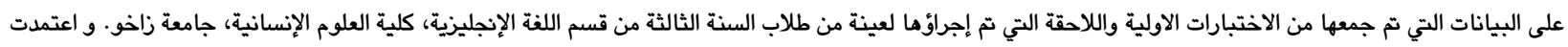

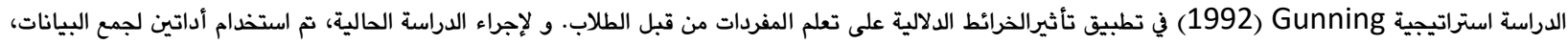

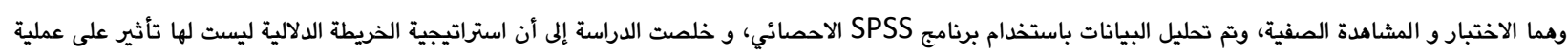
تعلم المفردات من قبل الطلاب. الكلمات الدالة: تعلم الكلمات، الخرائط الدلالية، وعي الطلاب.

\section{فيُربوونا يـهيثان بريّكا ستراتيجيا نهخشاندنا سيمانتيكى}

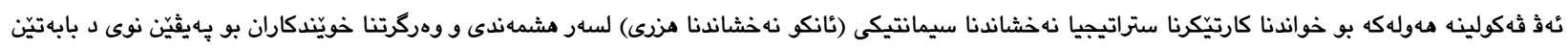

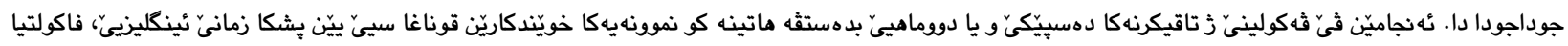

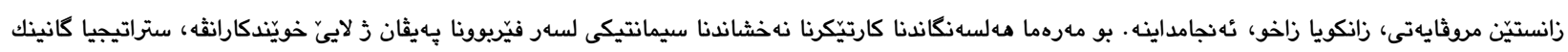

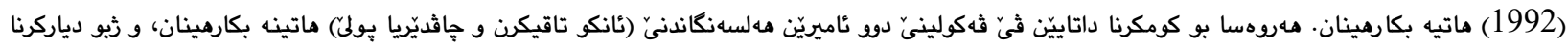

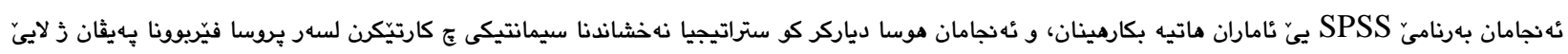
خويّندكارانثه نينه.

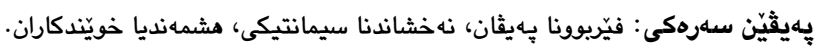

